\title{
Geopoliticas de la identidad: La difusión de acciones afirmativas en los Andes ${ }^{1}$
}

\author{
Manuel Eduardo Góngora $\mathbf{M e r a}^{2}$ \\ Freie Universitat, Berlín, Alemania ${ }^{3}$ \\ manuelgongora@hotmail.com \\ Recibido: 23 de julio de 2013 \\ Aceptado: 16 de agosto de 2013
}

1 Este artículo de investigación analiza las asimetrias de poder-saber que se pueden observar en el proceso de difusión de normas y políticas de acción afirmativa de base etno-racial en la región andina. El artículo resume algunos de los resultados de una investigación postdoctoral titulada "Difusión coevolutiva de estándares normativos sobre la prohibición de discriminación y la acción afirmativa en América Latina”, adelantada entre 2010 y 2012 dentro de la Red Internacional de Investigación sobre Desigualdades Interdependientes en América Latina (desiguALdades.net) en el Ibero-Amerikanisches Institut (Berlin), con estancias de investigación en Bolivia, Chile, Colombia, Ecuador, Perú y Suiza (UNRISD, Naciones Unidas).

2 Doctor en Derecho Público (summa cum laude) de la Humboldt-Universität zu Berlín.

3 Investigador postdoctoral y docente del Lateinamerika-Institut (Freie Universität Berlin). 


\title{
Geopoliticas de la identidad: La difusión de acciones afirmativas en los Andes
}

\section{Resumen}

Bajo una lectura Foucaultiana del nexo poder-saber, este artículo conjuga la teoría de difusión y el análisis del discurso para estudiar las asimetrias de conocimiento presentes en el proceso de difusión de acciones afirmativas de base etno-racial en países andinos seleccionados. El estudio pretende mostrar los entrelazamientos transnacionales entre discursos jurídicos y/o académicos y representaciones etno-raciales, basado en el análisis de reformas constitucionales y legislaciones recientes, la revisión bibliográfica de producción académica nacional y entrevistas a líderes de organizaciones indígenas y afrodescendientes, así como a funcionarios de entidades públicas relacionadas con políticas etnoraciales y antidiscriminatorias. En todos estos niveles (derecho, ciencias sociales, movimientos sociales, políticas públicas) la evidencia obtenida revela cómo el conocimiento experto posiciona a Estados Unidos como paradigma o modelo, invisibilizando la experiencia de otros países y dictaminando una agenda multiculturalista liberal. Esta transferencia (vertical, unilateral) de conocimiento ha tenido un impacto notable en Colombia y Chile, pero ha sido resistida por proyectos epistémicos alternativos, especialmente en Ecuador y Bolivia.

Palabras clave: Poder/saber, Acción afirmativa, Multiculturalismo liberal.

Palabras clave descriptores: Etnicidad, Multiculturalismo, Identidad cultural, Geopolítica, Poder político.

\section{Geopolitics of Identity: the Dissemination of Affirmative Actions in the Andes}

\begin{abstract}
Under a Foucauldian reading of the power-knowledge nexus, this paper combines the diffusion theory and the discourse analysis to study knowledge asymmetries present in the diffusion process of ethnoracial affirmative actions in selected Andean countries. The study aims to show the transnational connections between legal and / or academic discourses and the ethno-racial representations, based on the analysis of recent legislation and constitutional reforms, a literature review of national academic production and interviews with leaders of indigenous and Afro-descendant organizations as well as with servants of public companies related to ethno-racial and anti-discrimination policies. At all these levels (law, social sciences, social movements, public policies) the obtained evidence reveals how expert knowledge places the U.S.A. as a paradigm or model, obscuring the experience of other countries and ruling a liberal multiculturalist agenda. This transfer (vertical, unilateral) of knowledge has had a notable impact in Colombia and Chile, but it has been resisted by alternative epistemic projects, especially in Ecuador and Bolivia.
\end{abstract}

Keywords: Power / Knowledge, Affirmative Action, Liberal Multiculturalism.

Key words plus: Ethnicity, Multiculturalism, Cultural identity, Geopolitics, Political power.

\section{Geopoliticas da identidade: A difusão de ações afirmativas nos Andes Resumo}

Sob uma leitura Foucaultiana do nexo poder-saber, este artigo combina teoria de difusão e análise do discurso para estudar as assimetrias do conhecimento presente no processo de difusão de ações afirmativas de base etno-racial em países andinos seletos. O estudo visa mostrar os entrelaçamentos transnacionais entre discursos jurídicos e/ou acadêmicos e representações etno-raciais ao se basear na análise de reformas constitucionais e legislações recentes, a revisão bibliográfica de produção acadêmica nacional e entrevistas a lideres de organizações indígenas e afrodescendentes, bem como a funcionários de entidades públicas relacionadas com políticas etno-raciais e antidiscriminatórias. Em todo nivel (direito, ciências sociais, movimentos sociais, políticas públicas) a evidência obtida revela que o conhecimento perito posiciona aos Estados Unidos como paradigma ou modelo, invisibilizando a experiência dos outros países e ditando uma agenda multiculturalista liberal. Esta transferência (vertical, unilateral) do conhecimento teve impacto notável na Colômbia e Chile, pero esta sendo resistida por projetos epistêmicos alternativos, especialmente no Equador e a Bolivia.

Palavras-chave: Poder/saber, Ação afirmativa, Multiculturalismo liberal.

Palavras-chave descritores: Etnia, Multiculturalismo, Identidade cultural, Geopolítica, Poder político. 


\section{Introducción}

La cuestión racial ha ganado relevancia jurídica desde hace algunos años en América Latina, una región en la que el mestizaje fue tradicionalmente celebrado y la discriminación racial fue negada oficialmente por largo tiempo (Dulitzky, 2001). Esta relevancia se refleja en la aparición y posicionamiento del concepto de acción afirmativa de base racial o étnica en el discurso legal y académico. Las inquietudes que se despertaron con la introducción de politicas afirmativas basadas en la conciencia racial o étnica no se reducen solamente a la validez y aplicabilidad de estas categorias en el contexto latinoamericano, sino que además versan sobre la forma, en sí misma, en que ha tenido lugar su recepción en la región.

El comienzo del debate académico puede fijarse en el ensayo de Bourdieu y Wacquant "On the Cunning of Imperialist Reason" ("Sobre las argucias de la razón imperialista") (1999) ${ }^{4}$, en el que los autores criticaban la dependencia académica y exportación etnocéntrica de versiones norteamericanas de acción afirmativa hacia América Latina (a través de fundaciones estadounidenses, académicos estadounidenses y latinoamericanos educados en universidades de los Estados Unidos) porque esto implicaba también la diseminación de las identidades raciales binarias estadounidenses (White / Non white) hacia una región caracterizada por el mestizaje, donde los limites de las categorias etno-raciales siempre han sido mucho más ambiguos. Según esta línea argumentativa, las asimetrias de poder-saber explicarian la transferencia hacia América Latina de teorías, normas y politicas públicas desarrolladas en los Estados Unidos, cuyas categorias analíticas (en particular la concepción binaria de raza y las rígidas reglas de clasificación racial como la one-drop-rule) son ajenas a la región. Esto sugeriría que la promoción estadounidense de acciones afirmativas de base racial se trataría en realidad de una exportación (o incluso imposición) de desigualdades a través de la racialización, acentuando los conflictos sociales en la medida en que enfatiza las diferencias intergrupales y produce nuevas formas de desigualdad intragrupales.

La tesis de Bourdieu y Wacquant sobre la americanización del derecho anti-discriminatorio global generó un agitado debate en Brasil, cuya academia fue directamente aludida (cf. v.gr. Healey, 2000; Pinho

\footnotetext{
4 El ensayo era una traducción del texto de Bourdieu y Wacquant "Sur les ruses de la raison imperialiste", publicado en 1998 en Actes de la Recherche en Sciences Sociales como parte de algunas contribuciones sobre la hegemonía del neoliberalismo y la transferencia de tecnologias e instituciones estadounidenses a través de diversos canales (fundaciones filantrópicas, expertos en Estado de Derecho, medios masivos, etc.).
} 
y Figueiredo, 2002; Santos, 2002; Sansone, 2002, 2003; Guimarães 2005); además este país comenzaba a implementar sus primeros programas de acción afirmativa en educación superior y a introducir reformas institucionales para posicionar las temáticas relacionadas con las desigualdades raciales en la agenda nacional (incluyendo el establecimiento de la Secretaria de Politicas de Promoção da Igualdade Racial, SEPPIR). Las respuestas a las aseveraciones de Bourdieu y Wacquant fueron muy diversas, pero en general controvertian la idea de la recepción acrítica de las políticas afirmativas estadounidenses en Brasil. Si bien se reconoce alguna influencia del movimiento de derechos civiles en Estados Unidos, la adopción de acciones afirmativas no sería una emulación vertical de concepciones raciales foráneas, sino que estaría ligada a procesos de construcción de identidades vinculadas con los movimientos indígenas y afro en la región y en consecuencia, sería el resultado de dinámicas endógenas, fruto de décadas de luchas de distintas organizaciones y movimientos sociales que develaron progresivamente las desventajas sociales que enfrentan diversos grupos poblacionales por su color de piel y que finalmente fueron capaces de influir el debate político y normativo. La adopción de acciones afirmativas atendería entonces a dinámicas socio-históricas nacionales.

Pese a las críticas generalizadas contra la tesis de la americanización, algunos eventos posteriores al texto de Bourdieu y Wacquant podrian interpretarse como verificaciones de algunos de sus argumentos. Por ejemplo, la notoria influencia de organizaciones internacionales y fundaciones establecidas en Washington, de miembros del Congreso de los Estados Unidos y think-tanks estadounidenses en la diseminación de acciones afirmativas en diversos países latinoamericanos. Algunos analistas han observado también que la convergencia entre la Conferencia Mundial contra el Racismo (en adelante CMR) de Durban en 2001 y los ataques del 9/11 tuvieron un fuerte impacto en el proceso post-Durban en América Latina, debido a la exacerbación de iniciativas imperialistas dada la creciente influencia de halcones neoconservadores al interior del gobierno estadounidense (cf. Lao-Montes, 2009, pp. 227-228). Más aún, si estas tendencias de la década del 2000 confirman argumentos centrales de la tesis de la americanización, el rompecabezas se complejiza dado que la acción afirmativa en Estados Unidos ha sufrido un proceso de involución desde la década de $1990^{5}$ y en particular, la administración Bush

El punto de inflexión puede fijarse en la sentencia Adarand Constructors $v$. Peña, 515 U.S. 200 (1995), donde la Corte Suprema de Estados Unidos estableció el estándar de escrutinio estricto para programas federales de acción afirmativa basados en la raza o la etnia. Posterior a esta 
se opuso abiertamente a las políticas afirmativas e impulsó a nivel doméstico race-neutral measures (medidas neutrales en el aspecto racial). Entonces, ¿cómo entender la contradicción entre la agencia directa de los Estados Unidos en la exportación de conocimiento, normas y políticas públicas que simultáneamente son desmanteladas o incluso prohibidas a nivel doméstico? Siguiendo el argumento de la mala fe expuesto por Bourdieu y Wacquant, ¿esta exportación consciente de bad policies ${ }^{6}$ podría ser la prueba fehaciente de las argucias de la razón imperialista?

Este artículo utiliza categorias analíticas de la teoría de difusión (especialmente los conceptos de transferencia - $c f$. Nelken y Feest, 2001; Lütz, 2007- y difusión -cf. Twining 2005; Knill, 2005; Elkins y Simmons, 2005-) para estudiar las asimetrias de conocimiento del proceso de difusión de acción afirmativa de base etno-racial en la región andina. $\mathrm{El}$ artículo pretende ofrecer una mirada alternativa sobre cómo la acción afirmativa se ha estado difundiendo a través de la región, en particular en los países andinos.

La tesis de la americanización acierta al subrayar las asimetrias de conocimientos involucradas en el proceso; empero, al abordar la cuestión como una mera transferencia (jerárquica y unidireccional entre dos Estados, con énfasis en el país exportador como estándar prácticamente invariable y en relación de superioridad cognitiva con el receptor), tiene dos puntos ciegos: 1) simplifica extremadamente el proceso al suponer que la acción afirmativa es emulada o impuesta sin mayor resistencia local (o sin que tal resistencia pueda ser efectiva), y lo reduce a un proceso gestionado desde arriba (invisibilizando décadas de luchas sociales contra la discriminación y las desigualdades); y 2) equipara al país exportador como país creador de la innovación normativa (esto es, asume que la acción afirmativa tuvo su origen en los Estados Unidos, replicando la invisibilización que el propio conocimiento occidental ha hecho de la variada experiencia y conocimiento de países asiáticos y africanos sobre la materia). Por su parte, el punto ciego de la perspectiva endógena (que reduce la adopción de acciones afirmativas a dinámicas domésticas, con actores e instituciones nacionales más o menos independientes de influencias externas) radica

decisión, algunos estados han llegado a prohibir acciones afirmativas, como California (Propuesta 209/1996), Washington (Iniciativa 200/1998), Michigan (Iniciativa de Derechos Civiles de 2006), Nebraska (Iniciativa de Derechos Civiles de 2008) y Arizona (Propuesta 107/2010).

6 Bad policy se define como una política que se sabe previamente que es menos óptima en términos de alcanzar los fines para los cuales se adopta si se compara con políticas alternativas disponibles y cuya implementación crea nuevas problemáticas (o exacerba las existentes), requiriendo acción gubernamental adicional (cf. Schrad, 2010, p. 12). 
precisamente en su nacionalismo metodológico, dejando fuera de foco las dinámicas transnacionales que permean el proceso local.

Estas reflexiones se combinan con el análisis del discurso, bajo una lectura Foucaultiana del nexo poder-saber. El estudio pretende mostrar los entrelazamientos transnacionales entre discursos jurídicos y/o académicos y representaciones etno-raciales, basado en el análisis de reformas constitucionales y legislaciones recientes, la revisión bibliográfica de producción académica nacional y entrevistas a líderes de organizaciones indígenas y afrodescendientes, así como a funcionarios de entidades públicas relacionadas con políticas etnoraciales y antidiscriminatorias.

Bajo esta perspectiva, la difusión de acciones afirmativas aparece como un proceso caracterizado por tensiones de poder-saber que privilegian o invisibilizan los diversos conocimientos, discursos y conceptos en circulación, dependiendo de cómo son contestados, aceptados, practicados y/o adaptados localmente. Esta sensibilidad por la dimensión epistemológica puede dar luces acerca de cómo ciertos discursos teóricos logran un posicionamiento hegemónico en ciertos contextos y cómo otras alternativas terminan invisibilizadas. Para poder avanzar en esta línea, es preciso deconstruir el discurso académico occidental y la semántica de la acción afirmativa que la posicionan como una innovación estadounidense, invisibilizando las experiencias asiáticas en su concepción y diseño (sección 1).

Posteriormente, se analiza cómo las asimetrías de poder-saber contribuyeron a que la acción afirmativa llegara a América Latina en la década de 1990 en su variante multiculturalista liberal norteamericana (Costa, 2012), como parte de un set de políticas focalizadoras para eliminar la pobreza extrema garantizando el acceso al mercado a grupos marginados, empleando categorias rígidas de identidad grupal (como la raza o la indigeneidad) como criterios de focalización de la población objetivo (sección 2). Finalmente, se analizarán las tensiones y resistencias que este proceso de transferencia de conocimiento ha generado frente a proyectos epistémicos alternativos como la interculturalidad, la descolonización y el conocimiento desde adentro, especialmente en Ecuador y Bolivia (sección 3). 


\section{Geopolíticas de la identidad y acción afirmativa}

La identidad es un campo de contestación geopolítico de alcance global, una pugna entre poderes que tratan de imponer sus verdades a cuerpos que se encuentran. El condicionamiento epistemológico de la identidad a las nociones de indigeneidad y raza es el resultado de la expansión colonial europea en América y la trata transatlántica de africanos. Desde ese entonces, las identidades raciales y étnicas han sido definidas, demarcadas y construidas en un estado de fuerzas contrapuestas en el que la población colonizadora se tomaba así misma como punto de referencia para categorizar taxonómicamente a las poblaciones humanas en los territorios que iba conquistando (Hall, 1996). Las asimetrías de poder intrínsecas a los procesos de conquista y colonización produjeron estructuras jerarquizadas del ser (nosotros versus los otros, representados respectivamente como sujetos plenos e ideales contrapuestos a seres incompletos) y asimetrias del saber, en la medida en que los conocimientos nativos eran subyugados (en el sentido Foucaultiano), y sistemáticamente invisibilizados por el conocimiento occidental (García, 2010).

En el siglo XIX estas asimetrías de poder-saber generaron las condiciones que permitieron que los discursos y representaciones raciales europeas se convirtieran en verdades científicas de validez universal (generalizables y transferibles). De este modo, a través del racismo científico, se logró legitimar el imperialismo a escala global. La subyugación de las poblaciones no-blancas estaba justificada en su inferioridad biológica y en su incapacidad de alcanzar un estado superior de civilización y autogobierno. Esto se hace evidente particularmente en el caso de África, cuyos reinos fueron reducidos a la escala de tribus -lo que implica unidades primitivas-, sus religiones fueron categorizadas como animistas y fetichistas, y sus aportes culturales fueron invisibilizados a través, por ejemplo, de la teoría hamítica (Niane, 1984, pp. 12-14).

Este ordenamiento jerarquizado de las identidades, avalado por la ciencia hegemónica occidental y reforzado por las representaciones populares y los discursos antitéticos de algunos area studies en las potencias imperialistas -la construcción europea de oriente como inversión negativa y defectuosa de occidente (Said, 1978)-, fue difundido globalmente a través de la arquitectura colonial en África, Asia y Oceanía y abrazado por las élites eurodescendientes en las repúblicas independientes en América, lo que generó expresiones locales tan variadas 
como las leyes de Jim Crow en Estados Unidos o las políticas asimilacionistas y de blanqueamiento latinoamericanas.

La acción afirmativa es una política identitaria que recurre precisamente a esas categorias, las reafirma y disciplina bajo sus propios condicionamientos y lógicas. Interpretadas a la luz de estos antecendentes históricos, las acciones afirmativas rememorarian las geopolíticas identitarias occidentales de asignar a los otros una identidad etno-racial tribal, atrasada y primitiva, que afecta a los beneficiarios de estas políticas ya que construye su identidad a partir de la imagen que de ellos tienen sus benefactores, y los lleva a adaptarse a ese modelo de identidad para acceder a las prerrogativas concedidas por el Estado, lo que a su vez contribuye a perpetuar estereotipos de incapacidad, debilidad e inferioridad.

En términos generales, las políticas preferenciales de base etnoracial fueron ajenas a Latinoamérica durante gran parte del siglo XX; sólo desde hace algunos años han entrado en el discurso legal de algunos países. Si bien Brasil es el caso más conocido, algunos países de la región andina también han adoptado políticas afirmativas. En Colombia el artículo 13 de la Constitución de 1991 introdujo medidas afirmativas a favor de "grupos discriminados o marginados" (Wiesner, 2007), pero su aplicación bajo categorías etno-raciales es mucho más reciente, en particular desde: el CONPES 3310/2004 titulado "Politica de Acción Afirmativa para la Población Afrocolombiana", el Acuerdo $\mathrm{N}^{\circ} 319 / 2005$-que extendió beneficios en el sistema de salud para afrocolombianos-, el Decreto 140/2006 -que concedió acceso especial a profesores afrocolombianos en el sistema nacional educativo-; el Decreto 4466/2007, que reconoció un puntaje adicional de 3\% en el proceso de selección para subsidios de vivienda a favor de familias con algún miembro afrocolombiano; y el Plan Nacional de Desarrollo 2010-2014, que estableció acciones afirmativas en la educación y el servicio público bajo criterios etno-raciales. Adicionalmente, algunos gobiernos municipales y distritales han introducido acciones afirmativas $^{7}$ y las universidades públicas más importantes del país han incorporado mecanismos preferenciales de base etno-racial ${ }^{8}$.

\footnotetext{
V.gr. en Bogotá: Acuerdo 175/2005 (que definió la obligación de implementar acciones afirmativas y politicas públicas especialmente dirigidas para afrocolombianos viviendo en Bogotá, $c f$. arts. 2 y 3); Acuerdo 308/2008 (Plan de Desarrollo "Bogotá Positiva: para Vivir Mejor," que dio continuidad a la propuesta de acciones afirmativas de la anterior administración); Decreto 151/2008 (adopción de los principios para el plan de acción afirmativa y la obligación de consulta con las comunidades afrocolombianas); Decreto 192/2010 ("Plan Integral de Acciones Afirmativas para el Reconocimiento de la Diversidad Cultural y la Garantía de los Derechos de la Población Afrocolombiana, Negra y Palenquera residente en Bogotá".

8 V.gr:: Universidad Nacional: cuota de $2 \%$ para miembros de grupos indigenas (Acuerdo 018/1999) y de $2 \%$ para afrocolombianos en cada programa (Acuerdo 019/2009); Universidad del Valle:
} 
En la Constitución ecuatoriana de 2008 se estableció la acción afirmativa en los artículos 11 (numeral 2) y 65, los cuales se han venido desarrollando a través del Plan Plurinacional de 2009 para Eliminar la Discriminación Racial y la Exclusión Étnica y Cultural, reglamentado por el Decreto 60 de septiembre 26 de 2009 (v.gr. acción afirmativa para pueblos indígenas, afroecuatorianos y montubios, incluyendo becas para educación superior; cuotas universitarias raciales de al menos 10\%, definido por el Ministerio de Educación, CONESUP y universidades públicas y privadas; puntos extras por identidad étnica para aspirantes a concursos públicos y cuotas para el acceso igualitario a empleos públicos y a los recursos financieros, según disposiciones de los Ministerios de Trabajo, de Desarrollo Social y el Banco Nacional de Fomento), en la Ley Orgánica de Educación Superior de 2010 (el art. 77 , que establece becas para al menos $10 \%$ de los estudiantes regulares de bajos recursos, y el art. 91, que establece acciones afirmativas para docentes indígenas y afroecuatorianos en el acceso a vacantes) y la Ley Orgánica de Educación Intercultural de 2011 (el art. 2, que establece acciones afirmativas como estrategia de inclusión de grupos étnicos y los arts. 77-97 sobre educación intercultural bilingüe). La ciudad de Quito también ha desarrollado iniciativas para impulsar politicas afirmativas de base etno-racial ${ }^{9}$.

En Bolivia, la Constitución de 2009 introdujo un amplio número de prerrogativas constitucionales a favor de los que denomina "pueblos indígena originario campesinos" (en adelante PIOC), incluyendo mecanismos de acción afirmativa, entre otras medidas. Estas han tenido desarrollo legal en los artículos 2 b y 5k de la Ley 045/2010, y se han implementado 16 programas concretos de manera descentralizada por responsabilidad intersectorial a través de los ministerios de gobierno. Los más importantes están a cargo del Ministerio de Desarrollo Productivo y Economía Plural (acción afirmativa para inversión productiva sin parámetro de costo-beneficio), Ministerio de Obras Públicas, Servicios y Vivienda (acción afirmativa en vivienda), Ministerio de Defensa (educación técnica y reglas especiales en el servicio militar obligatorio), y Ministerio de Educación (en particular, el desarrollo de las medidas especiales para PIOC consagradas en la Ley 070 de 2010,

cuota de 4\% para afrocolombianos y 4\% para indigenas en cada programa (Resolución 044/2007); Universidad de Antioquia: un cupo universitario para miembros de comunidades indígenas en cada programa (desde 1983) y dos cupos para afrocolombianos en cada programa (Acuerdo 236/2002). Diversas universidades también incluyen programas preferenciales de acceso a indígenas y afrocolombianos, como cursos preuniversitarios o la eliminación del requisito de puntajes minimos.

9 Cf. Resolución 653/2011 del Concejo Metropolitano de Quito. 
incluyendo las universidades indígenas contempladas en el artículo $60)$.

En Chile, las acciones afirmativas para indígenas se han concentrado en incrementar el acceso económico al sistema educativo a través de créditos y becas. Ya desde la Ley 19253 de 1993 (art. 33) se contemplaba que la ley de presupuesto podía considerar recursos especiales para financiar un programa de becas indígenas. El actual programa de becas indígenas está reglamentado por el Decreto 126 de 2005, que otorga a la Junta Nacional de Auxilio Escolar y Becas la administración de la Beca Indígena (que opera desde la educación básica hasta la universitaria) y la Beca de Residencia Indígena. También se contemplan subsidios relativos al aprovechamiento de aguas y para la construcción de obras de riego y drenaje en tierras indígenas desérticas. Diversas universidades ofrecen becas y programas preferenciales de acceso para indigenas ${ }^{10}$.

Si bien cada uno de estos programas estatales tiene características específicas, comparten el conocimiento experto en el que se basan, tomando a Estados Unidos como referente principal (por no decir exclusivo). Las publicaciones especializadas en estos países asumen la acción afirmativa como una innovación estadounidense que surge con el movimiento de derechos civiles. Pero esta narrativa dista de ser neutral ya que se enmarca en una confrontación geopolítica internacional sobre el concepto de igualdad y el sentido de la acción afirmativa.

\section{La acción afirmativa en la dialéctica entre Oriente y Occidente}

En efecto, contrario a la versión tradicional que se difunde en la academia occidental, las políticas de acción afirmativa no son una innovación estadounidense; acciones afirmativas han existido en otros países, incluso mucho antes que en los Estados Unidos. Las primeras normas de trato preferencial según categorias étnicas o raciales datan de los tiempos del Imperio Austro-Húngaro después de 1867 (Wandruszka y Urbanitsch, 1980) y de la Unión Soviética entre 1923 y 1939 (Martin, 2001). Adicionalmente, el Imperio Británico implementó medidas de acción afirmativa en algunas de sus colonias durante la primera mitad del siglo XX (en la India Británica desde 1927). Los belgas también introdujeron medidas de trato preferencial en Ruanda desde 1934.

10 V.gr. el Programa Rüpü de la Universidad de la Frontera y los programas de ingreso especial de las Universidades Arturo Prat (Iquique), Católica (Temuco) y la Universidad de Tarapacá (Arica). 
Estas políticas no fueron diseñadas primariamente para favorecer a grupos étnicos marginados, sino que tenían, como valor geopolítico estratégico, la función de prevenir revueltas nacionalistas y aminorar las presiones secesionistas al interior de organizaciones politicas muy extensas y garantizar de este modo la integridad territorial de imperios multiétnicos. En otros casos estas politicas estaban orientadas por el principio divide et impera, y se encaminaban a romper las estructuras de poder locales e impedir alianzas entre grupos étnicos que pudieran convertirse en una amenaza contra el poder colonial (v.gr. las preferencias británicas para la minoría tamil en Sri Lanka, o las preferencias a la minoria tutsi en Ruanda, que ahondarian los conflictos y disparidades sociales con la población hutu y derivarían en el genocidio de 1994).

India fue la primera democracia en el mundo que trató de combatir desigualdades sociales a través de políticas preferenciales (KennedyDubourdieu, 2006, p. 8). Dos años después de ganar su independencia del imperio británico, fueron incorporadas acciones afirmativas (reservations) en la Constitución de 1949. En este momento fundacional entraron en conflicto dos grandes paradigmas de igualdad: uno que seguía la tradición liberal occidental, fundado en la presunción de igualdad formal ("todos son iguales ante la ley") y que defendia Mahatma Gandhi; y un paradigma de inclusión real fundado en la idea de igualdad material (personas en condiciones similares deben ser tratadas por igual y en consecuencia, la ley no debe aplicarse necesariamente de manera idéntica a cada persona). Su defensor más notorio fue el jurista Bhimrao Ramji Ambedkar, uno de los primeros miembros de la casta de los intocables que logró acceder a la educación universitaria, fue redactor de la Constitución de India y fue el responsable de la inclusión de derechos preferenciales para las castas marginadas.

Básicamente, Ambedkar argumentaba que la igualdad formal era una ficción jurídica inapropiada para fundar una democracia en un país como la India cuya sociedad había sido dividida por siglos debido al sistema hindú de castas y que además fue sometida durante décadas a un poder colonial del que heredaron jerarquizaciones sociales adicionales (Hasan, 2009). Por eso se prohibió constitucionalmente el uso de la categoría intocable (art. 17) y se establecieron constitucionalmente algunas acciones preferenciales a favor de las castas marginadas (Schedule Castes como les denomina la Constitución), incluyendo reservas de plazas de trabajo en el sector público (art. 16, 1 y 4) y de plazas de estudio en instituciones educativas públicas (art. 15, 1 y 4). Según interpretación de la Corte Suprema de India, si bien 
las disposiciones constitucionales de acciones preferenciales fueron redactadas a modo de excepciones al derecho a la igualdad, debian ser interpretadas como componentes del derecho a la igualdad material (protección igualitaria de las leyes ${ }^{11}$ ) y como medidas contra desigualdades estructurales ${ }^{12}$.

La experiencia de India en materia de reservations fue relevante para otros países de su área de influencia, como Pakistán -en donde se establecieron politicas preferenciales desde la década de 1950, especialmente para favorecer el acceso de bengalis y sindhis al servicio público siguiendo una lógica geográfica (provincias de poco desarrollo) y fueron incluidas en el artículo 27 de la Constitución de 1973 ( $c f$. Sardar Ali y Rehman, 2001, p. 23, 29)-, Bangladesh (con políticas preferenciales a favor de población marginada bengali instauradas durante el período del Paquistán Oriental y que se mantuvieron después de la independencia en 1971), Indonesia y Malasia, en donde las preferencias establecidas por el Imperio Británico a favor de malayos originarios se mantuvieron en el artículo 153 de la Constitución de 1957 en forma de reservations en el servicio público y en el sistema educativo a favor de los bumiputeras (sons of the soil). El debate sobre acciones afirmativas (en forma de dominación malaya) fue una de las disputas políticas centrales durante la década de 1960, que llevaron finalmente a la separación de Singapur de Malasia en 1965 (Holst, 2012, p. 43).

Por su parte, a Estados Unidos le tomó tres lustros más que a la India (y cien años contando a partir de la Proclamación de Emancipación de Lincoln) lograr el consenso democrático necesario para poner fin al racismo de jure y la segregación racial. La literatura especializada estadounidense cita la Ley de Derechos Civiles de 1964 y la Orden Ejecutiva 11246 de septiembre 24 de 1965 como las bases normativas de las políticas de acción afirmativa en ese país. Sin embargo, la influencia de India en la adopción de políticas preferenciales en Estados Unidos es ampliamente ignorada, salvo en contados estudios comparativos que destacan algunos paralelismos ( $c f$. v.gr. Chandola, 1992; Jackson, 1999; Sowell, 2004). En casos aislados se hace alguna alusión tangencial a la influencia de Gandhi en el movimiento de derechos civiles estadounidense o se menciona la visita de Martin Luther King Jr. a la India en 1959, donde tuvo la oportunidad de conocer de primera mano

11 Cf. Corte Suprema de India, Chiranjit Lal Chowdhuri vs The Union of India and others, diciembre 4, 1950

12 Cf. e.g. Corte Suprema de India, State of Kerala y Anr vs N. M. Thomas and others, septiembre 19, 1975. Sobre el rol de los jueces en la definición legal de beneficiarios de acciones afirmativas y en la implementación de medidas compensatorias concretas, ver (Galanter 1984, pp. 188-281). 
la implementación de reservations (King, 1959). Recientemente se publicó una investigación que narra esta historia oculta de las conexiones entre activistas anticoloniales en India y activistas del movimiento negro en Estados Unidos durante este período (Slate, 2012), pero esta es apenas la excepción que confirma la regla.

A diferencia de la experiencia de la India, las acciones afirmativas estadounidenses no fueron concebidas originalmente como políticas distributivas o mecanismos de transformación social para superar desigualdades estructurales, sino como medidas reparativas o compensatorias ante las injusticias y disparidades heredadas del régimen segregacionista ${ }^{13}$, y como paliativos ante la discriminación de facto y la multiplicación de conflictos raciales y violencia interna, sin abandonar del todo el paradigma liberal de la igualdad formal y la confianza en las dinámicas del mercado. Esto se aprecia, por ejemplo, en el hecho de que los programas iniciales de acción afirmativa eran políticas regulatorias destinadas a incentivar ciertas conductas en los agentes económicos (en especial contratistas del gobierno), como por ejemplo incrementar las oportunidades de los afro-americanos en el acceso al mercado laboral, sin establecer cuotas o porcentajes de acceso ni comprometer fondos públicos sustanciales. Más aún, dado que no hubo reforma constitucional para incluir acciones afirmativas en la Constitución, se le concedió un papel sustancial a los jueces constitucionales a la hora de establecer los limites de estas políticas y su conformidad con la Constitución, incluyendo la prohibición del sistema de cuotas basado en categorias raciales ${ }^{14}$.

Lo anterior obligó a justificar las cuotas y otras medidas preferenciales bajo criterios como la promoción de la diversidad cultural, lo que permitió la inclusión de otras reivindicaciones ajenas al movimiento negro (v.gr. las demandas indigenas y de migrantes latinos y asiáticos). Pese a que en las décadas de 1960 y 1970 esto impulsó reformas educativas muy importantes (v.gr. el establecimiento de departamentos de estudios culturales en las universidades, propuestas de currículos no-eurocéntricos, inclusión de saberes de grupos excluidos), a finales de la década de 1980 este componente epistemológico transformador fue en gran parte anulado por politicas neoliberales -v.gr. reducción de los presupuestos de estos programas

13 Cf. v.gr. la definición de acción afirmativa en: U.S. Commission on Civil Rights Briefing Paper on Affirmative Action, Daily Lab. Rep. (BNA) No. 64, D-33 (Abril 4, 1995).

14 Cf. Corte Suprema de Estados Unidos. University of California Regents v. Bakke, 438 U.S. 265 (1978). 
y privatización relativa de las universidades públicas ( $c f$. Lao-Montes, 2011, pp. 131-132)-.

Adicionalmente, en contraste con el modelo de la India, la acción afirmativa en Estados Unidos era considerada una excepción al derecho a la igualdad y por lo tanto, una forma de discriminación, si bien benigna. El alcance geopolítico de esta distinción puede apreciarse en la postura que adoptaron estos dos países durante las negociaciones de los Pactos Internacionales de Derechos Humanos entre las décadas de 1950 y 1960. La representación estadounidense no promovió activamente la difusión de sus programas de acción afirmativa en estas plataformas internacionales y defendió una concepción liberal de la igualdad con énfasis en igualdad de oportunidades.

En contraste, países socialistas y post-coloniales defendieron una concepción de igualdad material con énfasis en igualdad de resultados. De hecho, el origen del actual artículo 26 del Pacto de Derechos Civiles fue una propuesta de la India de 1949 ( $c f$. Comisión de Derechos Humanos de las Naciones Unidas, 1949) que emulaba el artículo 14 de la Constitución de India y complementaba la propuesta occidental de "igualdad ante la ley" con el derecho a la "protección igualitaria de la ley". A pesar de los intentos de potencias occidentales por borrar esta segunda frase, finalmente se mantuvo en el artículo, si bien con algunas restricciones, v.gr. la inclusión de la expresión in this respect para tratar de evitar una cláusula de igualdad más fuerte (Tomuschat, 1981, pp. 695-716).

\section{Posicionando significados: la semántica de la acción afirmativa}

Como se ha visto, las asimetrias de conocimiento derivadas de tensiones geopoliticas explican la invisibilización de las experiencias orientales de politicas preferenciales en la literatura continental especializada y el derecho internacional. Pero la propia semántica de estas politicas preferenciales también denota las tensiones de poder-saber que derivaron en la adopción de la expresión acción afirmativa sobre otras alternativas.

Es muy usual en las publicaciones latinoamericanas especializadas (Wiesner, 2005, pp. 44-45; Claro y Seoane, 2005, pp. 56-57; González, 2006, p. 310; Almario, 2007, pp. 197-198; Williamson, 2007, pp. 79-80) introducir el estudio de las acciones afirmativas haciendo referencia a la Orden Ejecutiva 10925 de marzo 6 de 1961 como el primer documento legal estadounidense que empleó la expresión 
acción afirmativa y en ocasiones se subraya que el documento fue obra del Presidente John F. Kennedy, en cierto modo mitificando el texto gracias al aura carismática de Kennedy. En algunos casos se menciona que India, Sudáfrica u otros países han adoptado acciones afirmativas, pero no pasan de alusiones tangenciales (en ocasiones solo son citas de literatura secundaria), y en todo caso se mantiene la atención en Estados Unidos como modelo (Syss, 2003, pp. 111-112; Jaimes, 2007, pp. 45-50; Carmona, 2011, pp. 89-94; Walsh, 2011a, p. 213).

No solo llama la atención el que los expertos legales prefieran citar una Orden Ejecutiva de menor rango antes que referirse a una norma de jerarquía constitucional como los artículos 14-16 de la Constitución de India (o por qué no los mencionados artículos 27 de la Constitución de Pakistán o el 153 de la Constitución de Malasia). Lo más sorprendente es que al revisar el texto de la Orden Ejecutiva en cuestión solo se requiere a los contratistas del gobierno "to take affirmative action to ensure that applicants are employed, and that employees are treated during employment, without regard to their race, creed, color, or national origin". Es decir que el significante acción afirmativa solo designaba como significado una especial atención de los contratistas para evitar que hubiera discriminación racial en el empleo, pero en ninguna parte se hace mención de algún tipo concreto de medidas preferenciales de grupo bajo la responsabilidad del Estado, lo que es central para el concepto que ese término actualmente designa.

Más aún, el uso previo del término en Estados Unidos no tenía relación alguna con cuestiones raciales; la primera referencia oficial se remonta a 1935, en el marco de la legislación laboral sobre discriminación contra trabajadores sindicalizados ${ }^{15}$. Además de que el término no es unívoco (designa varios conceptos, por lo cual la relación entre denominación y concepto no es única), tampoco es monorreferencial, pues el concepto tiene denominaciones alternativas. En efecto, las politicas que se etiquetan como acciones afirmativas en Estados Unidos han sido adoptadas por distintos países bajo otras denominaciones: reserva, medida especial, tratamiento preferencial, discriminación positiva, acción positiva, discriminación compensatoria, equidad laboral, etc. Esto pone de manifiesto el hecho de que la expresión acción afirmativa no se impuso internacionalmente durante la última década debido a sus cualidades semióticas, sino probablemente a la hegemonía epistemológica de la academia estadounidense y a sus esfuerzos por transmitir su particular visión sobre políticas preferenciales a otros países.

15 Cf. 1935 National Labor Relations Act, section 10 c. 
Al respecto, pueden distinguirse dos grandes períodos. Durante la Guerra Fría, como ya se había advertido, la postura internacional estadounidense relativa al derecho a la igualdad y las acciones afirmativas estuvo alineada a sus intereses estratégicos como potencia del bloque capitalista. Por otro lado, para Europa y América Latina las políticas de acción afirmativa estadounidenses tenían poca relevancia para sus propias sociedades (Banton, 1999) bajo los discursos asimilacionistas y de homogenidad étnica que imperaban respectivamente en estas regiones. A nivel del derecho internacional, el consenso anti-racista de post-guerra (reflejado en el artículo 1,3 de la Carta de las Naciones Unidas), estaba orientado a combatir el racismo "en las mentes de los hombres" y destruir así "el dogma de la desigualdad de los hombres y de las razas" ( $c f$. Preámbulo de la Constitución de la UNESCO), por lo cual desde la Declaración de UNESCO de julio de 1950 titulada "La Cuestión Racial", se estableció que la raza no es un fenómeno biológico sino un mito social y en consecuencia, su semántica debía ser proscrita. Es por ello que el derecho internacional y las instituciones de las Naciones Unidas trataron de borrar la semántica racial y reducir su significancia política y social. Comprensiblemente, políticas públicas basadas en la conciencia racial no encajaban en este marco.

A finales de la década de 1980, con la caída del muro de Berlín, la euforia del final de la historia y del triunfo del modelo liberal liderado por Estados Unidos, algunos autores canadienses y estadounidenses (en particular Will Kymlicka, Charles Taylor, Iris Young y Nancy Fraser) se convirtieron en referentes globales sobre lo que debe entenderse como multiculturalismo, y el modelo de acción afirmativa estadounidense ganó visibilidad en las publicaciones especializadas, incluso en Europa (por ejemplo: Appelt y Jarosch, 2000; Hansen, 2004; Peters y Birkhäuser, 2005). Pese a que instituciones de la Unión Europea terminaron adoptando la terminologia de acción afirmativa, esta se ha asociado generalmente a politicas a favor de la mujer ${ }^{16}$, e incluso hay países europeos que prohíben las acciones afirmativas de base racial (v.gr. Eslovaquia) y el uso de estadísticas raciales (v.gr. Francia), en gran medida por la aprensión que sigue produciendo la palabra raza en paises que sufrieron los horrores del nazismo.

En Sudáfrica, el modelo estadounidense de acción afirmativa fue ampliamente influyente durante el fin del apartheid, pero su recepción

16 Excepcionalmente, el artículo 5 de la Directiva del Consejo Europeo 2000/43/EC de junio 29, 2000, permite a los Estados miembros adoptar medidas de acción positiva para prevenir o compensar disparidades raciales o étnicas. 
fue balanceada, ya que se tuvieron en cuenta las políticas preferenciales asiáticas, como lo demuestran las ponencias presentadas durante la conferencia de 1991 Affirmative Action in the New South Africa, que incluyó estudios críticos sobre India (e.g. L. Havanur, "India's Experiment with Protective Discriminatory Policy") y Malasia (e.g. M. Puthucheary, "Affirmative Action in Public Employment: The Malaysian Case").

En contraste, bajo la presión de las agencias internacionales de financiamiento, durante la década de 1990, América Latina profundizó las reformas neoliberales del Consenso de Washington (que propendían por políticas focalizadas de eliminación de la pobreza extrema en lugar de políticas universalistas de redistribución para combatir la desigualdad) y abrazó el modelo multiculturalista norteamericano, caracterizado por una concepción estática de cultura cuya autenticidad debe preservarse y que considera la diversidad cultural como un patrimonio o recurso de valor para el Estado. Este modelo encajaba con la lógica de figuras aún vigentes del periodo colonial como las reservas indigenas o los quilombos (encerrar culturas para que no desaparezcan ni se contaminen con influencias externas). A ello se suma una lógica economicista, que entiende las disparidades raciales como fallos de mercado (lo que justifica una intervención estatal transitoria en el sistema educativo y el mercado laboral) y que promueve acciones afirmativas como instrumentos para administrar eficientemente el potencial creativo de la diversidad cultural en instituciones públicas y privadas (diversity management).

En el caso concreto del sistema educativo, la acción afirmativa sería una medida compensatoria frente a los efectos de la privatización (que en aras de la rentabilidad del sistema excluye a personas de bajos recursos). De este modo, la imposición de una agenda de reformas estructurales dictadas por Washington instauró un nuevo ciclo de asimetrías de conocimiento entre Estados Unidos y Latinoamérica, marcado por la adopción del modelo de identidades rígidas, en consonancia con el modelo neoliberal de focalización de politicas públicas a través de categorías étnicas/raciales. 


\section{América Latina como área de influencia estadounidense en la difusión de la acción afirmativa}

A mediados de la década de 1990 las voces críticas en contra de la agenda neoliberal se multiplicaron en América Latina, especialmente debido a los efectos sociales de las reformas estructurales. Con el inocultable incremento de las desigualdades, organismos internacionales que producen conocimiento experto sobre la región (particularmente CEPAL, el Banco Mundial y el Banco Interamericano de Desarrollo, estos dos últimos con sede en Washington) comenzaron a producir estudios sobre desigualdad que incorporaban explícitamente categorias etno-raciales, encontrando evidencia empírica sobre la existencia de desigualdades raciales estructurales en América Latina. Diversas investigaciones concluyeron que los pueblos indígenas y afrodescendientes mostraban los peores indicadores socioeconómicos y que los pobres estaban sobre-representados entre estos grupos, por lo que las diferencias etno-raciales seguían siendo importantes para determinar las diferencias en el bienestar y las capacidades ${ }^{17}$.

Estos reportes tuvieron importantes repercusiones en las agendas de varios países latinoamericanos y en la recolección de datos estadísticos desagregados por categorías etno-raciales. El BM, el BID y la CEPAL promovieron entre los funcionarios de las agencias nacionales de estadística el reconocimiento estadístico de los grupos indígenas y afrodescendientes y la reforma de la metodología de censos para poder identificar sus necesidades específicas en políticas públicas, incluyendo acción afirmativa, bajo la bandera de la inclusión social. A este respecto, Walsh se pregunta lúcidamente cuáles son los vínculos entre el interés del BID en las políticas de inclusión etno-racial y el enfoque político central del BID (y el BM): el adelanto del modelo de desarrollo del libre mercado (Walsh, 2011b, p. 100).

A comienzos de la década del 2000, la relevancia que había ganado el tema de desigualdades raciales entre las agencias internacionales establecidas en Washington llevó a la conformación de la Inter-Agency Consultation on Race in Latin America (IAC), un grupo consultivo que incluía entre otros, al BM, el BID, el Diálogo Interamericano y el Departamento del Gobierno Británico para el Desarrollo Internacional. El grupo fue creado con el fin explícito de hacer recomendaciones de políticas públicas a los Estados latinoamericanos que se enfocaran

17 Entre muchos: Psacharopoulos y Patrinos (1994), Partridge, Uquillas y Johns (1996), Gacitúa, Sojo y Davis (2001), Ferranti (2003), Ferranti, Perry, Ferreira y Walton (2003), Hall y Patrinos (2005) y World Bank (2005). 
en las condiciones de vida de los afrodescendientes, incluyendo la promoción de políticas de acción afirmativa en la región (Inter-American Dialogue, 2003, pp. 3-5).

Uno de los retos detectados por el grupo era promocionar esos cambios en países que se estaban desalineando de los preceptos onesize-fits-all (talla única) del Consenso de Washington y que se mostraban más escépticos frente a recetas externas. En respuesta, se escogió como estrategia de difusión el apoyo financiero a numerosas organizaciones etno-raciales de base para mejorar su capacidad de lobby y negociación con sus gobiernos. La lógica de esta estrategia residía en la producción local de conocimiento experto que convenciera a sus respectivos gobiernos acerca de las ventajas de las políticas focalizadas sobre las politicas universalistas bajo las condiciones nacionales concretas (Davis, 2003, p. 9).

El financiamiento de las organizaciones de base no tenía que estar expresamente condicionado a la promoción de políticas de acción afirmativa (o a la adopción de teorías o categorías norteamericanas sobre raza o etnicidad) para que fuera un canal de difusión de políticas afirmativas à l'Américaine mucho más efectivo que la imposición directa de conocimiento experto, ya que el conocimiento producido por instituciones y organizaciones locales era recibido a nivel doméstico como conocimiento endógeno. Por eso la estrategia de apoyo a institutos de investigación y organizaciones de base también fue adoptada por fundaciones estadounidenses con presencia en la región, como MacArthur, Rockefeller, Kellogg y Ford.

Entre estas fundaciones, sin duda la más activa en la difusión de acciones afirmativas fue la Fundación Ford, a través de su iniciativa Pathways to Higher Education (Caminos hacia la Educación Superior), un programa global de promoción de acciones afirmativas en el sistema educativo, lanzado en 2001 y planeado a diez años. El programa debía aumentar sustancialmente el número de estudiantes provenientes de grupos marginados que lograban entrar a la universidad y culminar sus estudios. Su estrategia consistía en financiar grupos de investigación y centros de educación superior en la región que ya estuvieran trabajando con poblaciones etno-raciales. En Latinoamérica se escogieron organizaciones en Argentina, Brasil, Chile, Colombia, Costa Rica, Guatemala, México, Nicaragua y Perú (Didou, 2008). En términos generales, si bien el apoyo financiero de las fundaciones estadounidenses no implicaba automáticamente una dependencia intelectual de las organizaciones e instituciones locales, sí les generaba 
una cierta presión para presentar sus agendas y productos científicos de un modo que llamara la atención de su audiencia internacional y, en algunos casos, que se adaptara a las investigaciones que promovían los programas de apoyo financiero ( $c f$. v.gr. la producción académica de la Fundación Equitas en Chile ${ }^{18}$ ).

El sistema de Naciones Unidas también operó como canal de diseminación de acción afirmativa a escala global, especialmente a través de conferencias regionales e internacionales que proveyeron un espacio transnacional para el diálogo y la acción concertada entre diferentes actores interesados en introducir politicas con conciencia etno-racial (Harrison, 2012, p. 6). La Conferencia de las Américas contra el Racismo en Santiago (diciembre de 2000) y la CMR en Durban 2001 sirvieron para posicionar políticamente una identidad diaspórica africana en torno al concepto de afrodescendiente que fortaleció las alianzas entre organizaciones de distintos países (Davis, Paschel y Morrison, 2012, pp. 27-28). Ambas conferencias fueron financiadas por la Fundación Ford. De nuevo, esto no necesariamente implica dependencia intelectual y de hecho, varias organizaciones latinoamericanas hicieron explícito su deseo de mantener su autonomía frente a influyentes organizaciones afro estadounidenses como AfroAmérica XXI (Telles, 2003, p. 44).

Lo cierto es que en Santiago 2000 los Estados latinoamericanos oficialmente reconocieron por primera vez el fenómeno de discriminación racial y en Durban 2001 las acciones afirmativas terminaron incorporadas en la Declaración y el Plan de Acción global contra el racismo y la discriminación racial ( $c f$. Plan de Acción de Durban, párr. 5, 99 ss). Por ello, desde la perspectiva legal el sistema de Naciones Unidas resultó ser extremadamente efectivo como canal de diseminación del concepto de acción afirmativa; no obstante, en términos geopoliticos el tema parcialmente corrió la misma suerte del proceso Durban, que desde la primera conferencia en 2001 ha visto afectada su reputación por las posturas anti-semíticas defendidas en ese escenario. Más aún, como uno de los mayores donantes de la conferencia, la Fundación Ford recibió el grueso de las críticas de los medios estadounidenses. En respuesta, Ford redireccionó gradualmente sus fondos hacia tópicos políticamente más neutrales. Esto explicaría en buena medida el decreciente interés de las fundaciones estadounidenses en el apoyo

18 Cf. v.gr. Claro (2005), Claro y Seoane (2005), León y Holguín (2005), León y Hurtado (2005) y Jaramillo (2008). 
de iniciativas relacionadas con el proceso Durban en Latinoamérica (Davis, Paschel y Morrison, 2012, pp. 37, 40-41).

Además de la influencia de fundaciones estadounidenses, thinktanks y organizaciones financieras establecidas en Washington, el gobierno estadounidense participó directamente en la transmisión de acciones afirmativas hacia América Latina durante la década previa, ya que la situación de los afro-latinos entró en la agenda de su política exterior con los países del hemisferio (Ribando, 2005). La Inter-American Foundation (una agencia del gobierno estadounidense) ya había apoyado intercambios de información entre afrodescendientes de diversos países del continente, incluyendo un encuentro crucial para el establecimiento de redes hemisféricas que tuvo lugar en Montevideo, en diciembre de 1994, denominado Primer Seminario Continental sobre Racismo y Xenofobia. También financió varios encuentros entre líderes afro-latinos y miembros del Congressional Black Caucus (una organización que representa a los miembros afroamericanos del Congreso estadounidense) y mantiene un programa de becas de viaje para financiar la participación de representantes de grupos etnoraciales en eventos internacionales. Esos eventos han sido cruciales para la consolidación de una identidad diaspórica afrodescendiente a escala continental, que se acopla a una larga historia de intercambios entre Estados Unidos y países del Caribe angloparlante en el marco de un espacio cultural transnacional denominado en la literatura especializada como el Atlántico Negro (Gilroy, 1993/2002; Costa, 2007).

La Secretaría de Estado de Estados Unidos también ha incentivado programas focalizados en las disparidades etno-raciales. Por ejemplo, los acuerdos bilaterales contra la discriminación racial firmados con Brasil ${ }^{19}$ y Colombia ${ }^{20}$, que promueven el intercambio de conocimiento experto y best practices (mejores prácticas) ${ }^{21}$ entre las agencias nacionales que manejan esas temáticas.

Es importante mencionar que la confluencia entre la conferencia de Durban y los ataques del 9/11 generó un redireccionamiento de los recursos del gobierno estadounidense (especialmente los fondos del IAF y USAID) hacia regiones de importancia estratégica en la guerra contra

19 "U.S.-Brazil Joint Action Plan to Eliminate Racial and Ethnic Discrimination and Promote Equality", firmado en marzo de 2008 por Condoleezza Rice (Secretaria de Estado de Estados Unidos) y Edson Santos (Ministro de SEPPIR), ambos afrodescendientes.

20 "U.S.-Colombia Action Plan on Racial and Ethnic Equality", 2010.

21 El concepto en inglés refleja el origen de la idea de repetir modelos que alguna institución define como mejores que otros. 
el terrorismo, como el Medio Oriente (Davis, Paschel y Morrison., 2012, p. 41). Esto redujo la atención e influencia que Estados Unidos podía ejercer sobre Latinoamérica, lo que coincidió con la elección de varios gobiernos de retórica anti-imperialista interesados en tomar distancia de Estados Unidos ${ }^{22}$.

Solo un puñado de gobiernos mantuvieron una postura pro-estadounidense en su política exterior; el caso más notorio fue el del presidente colombiano Álvaro Uribe. Durante la década, Colombia se convirtió en el tercer mayor receptor de ayuda estadounidense a nivel mundial (en el marco de la guerra contra las drogas y la guerra contra el terrorismo), lo que consecuentemente otorgó a los actores estadounidenses mayores herramientas para intervenir en asuntos colombianos, incluyendo temas relacionados con afrocolombianos. Por esto, el caso colombiano estuvo caracterizado por dinámicas más verticales de transferencia en comparación con otras experiencias del continente.

Para ilustrar lo anterior se puede mencionar la negociación del TLC entre Colombia y Estados Unidos, que forzó al gobierno de Uribe a tomar algunas medidas a favor de los afrocolombianos para ganar los votos de los legisladores afroamericanos en el Congreso estadounidense; o la 2008 Consolidated Appropriations Act (FY2008, H.R. 2764/P.L. 110-161) que exigía al Departamento de Estado certificar que el ejército colombiano no estuviera violando el derecho a la propiedad y a la tierra de los indígenas y afrocolombianos, y prohibió el uso de fondos del programa andino antidrogas para la inversión en palma de aceite si causaba desplazamientos de estos grupos (como en efecto ocurrió en el Chocó, un departamento con alta presencia afrocolombiana).

Esto generó grandes incentivos para consolidar información desagregada en categorías etno-raciales y emplear una semántica de acciones afirmativas en los planes de desarrollo o de derechos humanos que pudieran servir como prueba de la voluntad gubernamental de reducir las disparidades etno-raciales; no obstante, muchas de las medidas etiquetadas como acciones afirmativas no eran más que politicas asistencialistas, y en gran medida se quedaban en mera retórica. Según algunos analistas, este interés particular en asistir a Colombia se ajustaba a las politicas hemisféricas estadounidenses, dado que se creaba un contrapeso a la influencia de Hugo Chávez en la región.

22 Hugo Chávez en Venezuela (1998, 2000, 2006 y 2012); Lula da Silva (2002 y 2006) y Dilma Rousseff (2010) en Brasil; Néstor Kirchner (2003) y Cristina Fernández (2007) en Argentina; Tabaré Vázquez (2004) y José Mujica (2009) en Uruguay; Evo Morales en Bolivia (2005 y 2009); Daniel Ortega en Nicaragua (2006), Rafael Correa en Ecuador (2006, 2009 y 2013), y Fernando Lugo en Paraguay (2008). 
En la práctica, esto generó una dicotomía ideológica entre las organizaciones afrodescendientes, lo que tuvo un impacto significativo en los discursos sobre políticas raciales que circulaban en la región ( $c f$. LaoMontes, 2009, pp. 210-211; García, 2008).

En conclusión, tanto instituciones públicas y privadas estadounidenses como organizaciones internacionales con base en Washington han jugado un papel muy significativo en la diseminación de acciones afirmativas en Latinoamérica. Sin embargo, el proceso de transferencia ha ocurrido en el marco de patrones de poder cambiantes en la región, debido a la influencia limitada de Estados Unidos después de los ataques del 9/11 y al giro a la izquierda latinoamericano. La siguiente sección analiza cómo estas dinámicas geopolíticas cuestionaron las políticas de conciencia racial promovidas por Estados Unidos y contribuyeron a la circulación de políticas alternativas basadas especialmente en conocimientos indígenas, generando tensiones y conflictos epistemológicos.

\section{Conflictos epistemológicos entre conocimiento exógeno y endógeno en la región andina}

La recepción de las acciones afirmativas en Latinoamérica no se ha dado sin el surgimiento de resistencias. Particularmente, la región andina se ha convertido en los últimos años en uno de los escenarios más activos de confrontación epistemológica entre el paradigma neoliberal estadounidense (cuya hegemonía es muy notoria en Chile, Colombia y en alguna medida en Perú) y el paradigma anti-neoliberal fundado en discursos locales que proponen modelos alternativos de organización socio-económica y política con base en conocimiento situado (en especial indígena). Este incluye entre otros, los conceptos de Pachakuti ("cambio", entendido como tiempo y espacio que retorna), sumak kawsay (quechua), suma qamaña (aymara) y la subjetividad de la Pachamama, lo que se opone a la acumulación de capital mediante la explotación indiscriminada de recursos naturales ( $c f$. Walsh, 2009, p. 169), con sus expresiones más elaboradas en las Constituciones de Ecuador y Bolivia ${ }^{23}$.

En Colombia y Chile se han introducido politicas de acción afirmativa bajo el modelo multiculturalista norteamericano (preservación

23 El principio del buen vivir fue introducido tanto en la Constitución de 2008 de Ecuador (arts. 275-278) como en la Constitución de 2009 de Bolivia (arts. 8, 80, 306 y 313). 
de la diversidad cultural como recurso valioso ${ }^{24}$, bajo concepciones rígidas de raza y cultura), estableciendo como objetivo central el incremento del acceso a la educación terciaria (y por derivación al mercado laboral) a minorias etno-raciales. El resultado esperado es el aumento progresivo de su participación en los espacios de decisión política y social, siguiendo una lógica de empoderamiento económico de una minoría dentro de una minoría.

Para la definición del target group suelen escogerse criterios esencialistas de tipo checklist, y corresponde a una entidad estatal la constatación del estatus de una persona o grupo como indigena o afrodescendiente. Por ejemplo, la Corporación Nacional de Desarrollo Indigena (CONADI) en Chile expide el "Certificado de acreditación de la calidad indigena" a individuos que demuestren cumplir los requisitos legales para ser reconocidos como indígenas para poder postularse para acciones afirmativas.

En Colombia el Ministerio del Interior lleva un registro oficial de las comunidades indígenas reconocidas por la Dirección de Asuntos para las Comunidades indígenas, Rom y Minorías y un registro oficial de las comunidades negras reconocidas por la Dirección de Asuntos para las Comunidades Negras, Afrocolombianas, Raizales y Palenqueras. Este registro es fundamental para el ejercicio de derechos colectivos como la consulta previa y en algunos casos, para ser elegibles como receptores de acciones afirmativas ${ }^{25}$. Los estudios sobre desigualdad racial en ambos países básicamente hacen eco del debate académico y político estadounidense que cuestiona la acción afirmativa en sí (se discute si deben adoptarse o no acciones afirmativas y si son compatibles con el principio de igualdad de oportunidades en sociedades orientadas por el mérito).

Especialmente en Colombia, este debate ha tenido lugar en la arena judicial debido al rol protagónico que juega la Corte Constitucional en la arquitectura institucional del país y a su intervención activa en la implementación de políticas con enfoque diferenciado para proteger grupos etno-raciales de los efectos del conflicto armado interno ${ }^{26}$. Tal enfoque sigue muy de cerca la jurisprudencia de la Corte Suprema

24 En Colombia la Corte Constitucional incluso ha llegado a considerar a los indígenas como "recurso natural”, cf. Sentencia T-342/1994. Agradezco a Diana Bocarejo por esta observación.

25 Igualmente, en Perú corresponde al Viceministerio de Interculturalidad elaborar la Base de Datos Oficial de comunidades reconocidas como pueblos indigenas ( $c f$. Decreto Supremo DS 001-2012$\mathrm{MC}$ ), siguiendo criterios objetivos como el mantener estilos de vida y vínculos espirituales con el territorio tradicionalmente ocupado ( $c f$. art. 7 de la Ley 29785).

26 Cf. Corte Constitucional de Colombia, Sentencia T-025/2004; Auto 004/2009 y Auto 005/2009. 
de Estados Unidos; por ejemplo en materia de discriminación indirec$\operatorname{ta}^{27}$ (como fue teorizada por la Corte estadounidense en la década de $1970^{28}$ ) y la doctrina de escrutinio judicial estricto (según la cual la "raza" es considerada una categoría "inherentemente sospechosa" ${ }^{29}$ ).

A nivel de la academia, el influjo de las teorias y metodologías estadounidenses sobre la cuestión racial es innegable en numerosas investigaciones domésticas. Como ilustración puede tomarse la influencia de los estudios sobre discriminación racial del proyecto PERLA, Project on Ethnicity and Race in Latin America, liderado desde la Universidad de Princeton por Edward Telles (Program Officer de la Fundación Ford en Brasil entre 1997 y 2000), donde entrevistadores profesionales clasificaron por tono de piel a unos 40,000 encuestados latinoamericanos con base en una paleta de once colores. Finalmente, a nivel de la opinión pública, la acción afirmativa no ha generado mayores controversias, salvo algunos casos aislados que acaparan temporalmente la atención mediática.

En la medida en que estas políticas se han acomodado bajo la retórica de la superación de la pobreza, la inclusión social y el desarrollo económico, han recibido la aprobación del grueso de la población. Las resistencias se han reducido a los actores sociales que no encajan propiamente en los rígidos marcos etno-raciales promovidos por los gobiernos; particularmente los campesinos pobres han protestado en ambos países por la distribución preferencial de tierras a sus vecinos indígenas y afrodescendientes (Bocarejo, 2011; Ojeda, 2012) y por los accesos privilegiados a la educación (en particular las becas y subsidios indígenas para educación primaria y secundaria en Chile).

En contraste, Ecuador y Bolivia se han distanciado abiertamente del multiculturalismo liberal y sus debates teóricos y políticos se desarrollan en el campo del pensamiento y los saberes. No se discuten los resultados empíricos de las investigaciones producidas por agencias internacionales o expertos noratlánticos, ni las recomendaciones legislativas y de políticas públicas que surgen a partir de esos estudios (incluyendo la implementación de acciones afirmativas); lo que se refutan son los supuestos que posicionan ese conocimiento experto como central, neutral y universalmente válido en el campo de las ciencias sociales en América Latina porque ocultan el valor geopolítico

${ }^{27}$ Cf. v.gr.: Corte Constitucional de Colombia, Sentencia T-335/2000.

28 Cf. Corte Suprema de Estados Unidos, Griggs et al. v. Duke Power Company, Co 401 U.S. 424 (1971), marzo 8, 1971.

29 Cf. v.gr.: Corte Constitucional de Colombia, Sentencia T-110/2010. 
de este conocimiento situado y acallan otras voces a las que se les niega el estatus de conocimiento relevante al no encajar dentro de los cánones y paradigmas del cientificismo occidental.

La propuesta alternativa es la interculturalidad, que no solo supone intercambio entre saberes en condiciones de igualdad, sino que además promueve el rescate de la identidad indígena y afro y la rearticulación del conocimiento desde adentro. Esto postula una dialéctica entre el conocimiento que se ha producido sobre los grupos etno-raciales (particularmente en los centros académicos occidentales) y el conocimiento que dichos grupos producen sobre sí mismos (cf. García, 2010, pp. 7374). En este punto, lo que se cuestiona es que los académicos locales trasplanten, más o menos de manera acrítica, nociones, categorias y teorias pensadas bajo las condiciones de sociedades capitalistas postindustriales, para comprender y resolver las problemáticas de sociedades con dinámicas y realidades abismalmente diferentes.

La propuesta epistémica para evitar este tipo de extrapolaciones consiste en la rearticulación (retorno) de los saberes propios como parte de un esfuerzo de descolonización del pensamiento que haga visible el impacto que ha producido el colonialismo en términos de asimetrias de poder, del saber y del ser (Walsh, Schiwy y Castro-Gómez, 2002; Walsh, 2009; Walker, 2010, Spedding-Pallet, 2011). Esta propuesta intercultural y descolonizadora si bien afirma las identidades indígenas y negras, asimismo abre espacios para la inclusión de otras identidades híbridas con saberes propios, como el pueblo montubio en Ecuador, o la figura legal de pueblos indigenas originarios campesinos en Bolivia.

Ahora bien, en la medida en que las acciones afirmativas han sido defendidas localmente por diversas organizaciones de base, la forma en que se les recibe ha variado entre los países andinos. En países con una importante presencia afrodescendiente (como Colombia y Ecuador) generalmente las organizaciones afro han interpretado la acción afirmativa como una conquista de la diáspora africana en Estados Unidos y por lo tanto como un elemento endógeno, perteneciente a sus luchas continentales por la igualdad. Por eso muchas de sus demandas han sido traducidas en politicas afirmativas muy similares a las aplicadas en Estados Unidos ( $c f$. Decreto 60 de septiembre 26 de 2009 en Ecuador y Decreto 192/2010 en Bogotá).

En contraste, las organizaciones indígenas de países que cuentan con una alta auto-identificación indígena (como Ecuador y Bolivia) muestran una baja recepción (o abierto desinterés) de la semántica 
de la acción afirmativa y generalmente perciben estas medidas como expresiones de asistencialismo y paternalismo estatal que esconden la lógica y perspectiva neoliberal y que solo ofrecen paliativos ante las condiciones de desigualdad estructural de los grupos etno-raciales marginados. Es por ello que sus demandas no se traducen necesariamente en exigencias de políticas afirmativas como cuotas o accesos preferenciales en educación o empleo, sino que incorporan reformas mucho más ambiciosas sobre el modelo económico y la institucionalidad estatal; en otras palabras, al percibirse como mayorias no demandan inclusión sino poder.

En el caso concreto de las acciones afirmativas para el acceso a la educación superior, las organizaciones afro de los países andinos (en particular aquellas asociadas al Grupo Barlovento ${ }^{30}$ ) celebran las acciones afirmativas ya que pueden ser útiles para superar desigualdades en el corto plazo, pero consideran que son insuficientes puesto que se trata no solo de garantizar la presencia física de los afros e indigenas en las universidades, sino ante todo de asegurar su presencia intelectual, en los contenidos y debates académicos y al nivel de la enseñanza (Chala, 2011, pp. 48-50; Lao-Montes, 2011, pp. 133-136). Las respuestas que se discuten giran en torno a la idea de descolonizar la universidad y el conocimiento que en ella se produce (v.gr. aumentar la planta de profesores indigenas y afrodescendientes, incorporar la medicina tradicional indígena y afro en los estudios de medicina, incluir la historia indígena y afro como parte sustancial en los estudios de historia). Es en este marco y en la apertura de universidades dirigidas primordialmente a comunidades indígenas en el que se incorporan propuestas de educación intercultural en países como Bolivia y Ecuador.

\section{Conclusión}

Desde el comienzo del debate, las asimetrias de conocimiento han ocupado un lugar destacado en las explicaciones acerca de cómo la acción afirmativa se ha introducido en Latinoamérica, pero las tensiones epistemológicas con proyectos alternativos han recibido poca atención. A partir del análisis de los discursos que circulan sobre

30 El Grupo Barlovento es una red transnacional de líderes afro-suramericanos, establecida en 2003, que sigue un enfoque filosófico de africanidad global, que critica el rol hegemónico de las perspectivas eurocéntricas sobre cultura e identidad y que busca promover una autopercepción afrodescendiente a partir del conocimiento endógeno. 
las acciones afirmativas en los países andinos seleccionados, este artículo ha demostrado el rol crucial que juegan las asimetrias de podersaber y las tensiones emergentes entre intereses estadounidenses y domésticos en la región.

Pese a las pretensiones de neutralidad y transferibilidad, el conocimiento experto producido por las agencias internacionales y las fundaciones filantrópicas estadounidenses sobre la acción afirmativa es un conocimiento situado (anclado al sitio desde el cual se produce, con las especificidades de su lugar de enunciación) y debería ser abordado como tal por la academia latinoamericana. En consecuencia, es necesario develar las lógicas neoliberales y economicistas que se encubren bajo una semántica de derechos e inclusión social. En este punto comparto las criticas de autores postcoloniales que cuestionan el supuesto de neutralidad de la ciencia occidental y abogan por una mayor inclusión epistemológica. Sin embargo, esto no debe conducir a un fundamentalismo anti-occidental, al desconocimiento de los aportes del pensamiento occidental o al rechazo indiscriminado de los estudios producidos por la academia norteamericana o las agencias internacionales sobre América Latina; se trata de abordar críticamente este conocimiento, develar sus intereses geopolíticos, identificar sus limitaciones en el marco de la experiencia histórica latinoamericana y considerar formas alternativas de comprender el mundo (Díaz, 2011, p. 23). El riesgo de la propuesta descolonizadora andina radica precisamente en que, en lugar de generar una relación intercultural, se desconozca sistemáticamente el conocimiento occidental y se imponga hegemónicamente al conjunto de la sociedad un conocimiento indígena (que también es situado), sobre la base de que "todos somos indígenas" (Canessa, 2006).

Lo anterior no debe interpretarse ni como una oposición radical a la acción afirmativa en la región ni a los proyectos emancipatorios basados en el rescate de identidades etno-raciales. Las acciones afirmativas en la región andina responden a una realidad de discriminación histórica y contemporánea y en ese sentido, pueden contribuir a mejorar las oportunidades y condiciones de vida de millones de personas excluidas, pero hay que saber implementarlas bajo las condiciones locales específicas. El enfoque extremo en la experiencia estadounidense no solo genera extrapolaciones teóricas y metodológicas sino que impide evaluar de una forma más balanceada los éxitos y fracasos de las políticas afirmativas alrededor del mundo. Al aprender de esas experiencias se puede evitar cometer errores bien conocidos en otras latitudes, como por ejemplo limitarse a implementar acciones 
afirmativas en la educación terciaria sin considerar cómo aumentar la permanencia de miembros de grupos marginados y la calidad de la educación que reciben en los niveles de primaria y secundaria. Para ello se requiere diversificar las fuentes.

Por esto mismo, hay que descartar la idea de que tan solo con acciones afirmativas à l'Américaine se van a resolver las exclusiones de los grupos marginados en América Latina, ya que estas solo procuran el acceso igualitario al mercado y a las ventajas del desarrollo sin cuestionar las desigualdades sociales ni las causas estructurales de exclusión. La propia experiencia estadounidense muestra que este modelo de acción afirmativa configura una élite dentro del grupo excluido y la integra en la sociedad dominante para administrar la diversidad, pero no combate e incluso refuerza las disparidades intragrupales.

Finalmente, más allá de la discusión acerca de cuál sería el modelo de acción afirmativa más eficiente para reducir desigualdades estructurales, es necesario evaluar las representaciones identitarias que estas medidas promueven. Las rígidas categorias étnicas y raciales deberian ser repensadas en consideración a los esencialismos y a las manipulaciones identitarias que estas producen, así como a las distintas identidades no-étnicas, no-raciales e híbridas que están quedando excluidas. Esto no solo es relevante en contextos sociales como el colombiano donde el grupo social dominante se ha congraciado con la minoria indígena y afrodescendiente, pero que ha dejado al campesino por fuera del discurso multicultural y su movilización política se ha visto estigmatizada por la polarización del conflicto armado. También es aplicable en contextos donde no opera una concepción minoritaria y subalterna del indígena, por ejemplo, a partir de las nuevas relaciones identitarias en Bolivia, en las que los aymaras y campesinos que apoyan al gobierno gozan de privilegios constitucionales que se le niegan a los indígenas de tierras bajas, creando nuevas tensiones y conflictos, pero esta vez entre indígenas (Canessa, 2012). 


\section{Referencias}

Almario, O. (2007). Reparaciones contemporáneas: de la memoria de la esclavitud al cuestionamiento de la exclusión social y el racismo. En C. Mosquera y L. C. Barcelos (Ed.). Afro-reparaciones: Memorias de la esclavitud y justicia reparativa para negros, afrocolombianos y raizales (pp. 183-212). Bogotá: Universidad Nacional de Colombia.

Appelt, E. y Jarosch, M. (Eds.) (2000). Combating Racial Discrimination Affirmative Action as a Model for Europe. Oxford/New York: Berg.

Banton, M. (1999). Discrimination Entails Comparison. En T. Loenen y P. Rodrigues (Ed.). Non-Discrimination Law: Comparative Perspectives (pp. 107118). La Haya: Martinus Nijhoff.

Bocarejo, D. (2011). Dos paradojas del multiculturalismo colombiano: la espacialización de la diferencia indígena y su aislamiento político. Revista Colombiana de Antropología, 47 (2), 97-112.

Bonnett, A. (2006). The Americanisation of Anti-Racism? Global Power and Hegemony in Ethnic Equity. Journal of Ethnic and Migration Studies, 32 (7), 1083-1103.

Bourdieu, P. y Wacquant, L. (1999). On the Cunning of Imperialist Reason. Theory, Culture \& Society, 16 (1), 41-58.

Canessa, A. (2006). Todos somos indígenas: Towards a New Language of National Political Identity. Bulletin of Latin American Research, 25 (2), 241-263.

Canessa, A. (2012). Conflict, Claim and Contradiction in the New Indigenous State of Bolivia. desiguALdades.net Working Paper Series, 22, Berlin: desiguALdades.net Research Network on Interdependent Inequalities in Latin America.

Carmona, C. (2011). Acciones afirmativas - Los primeros reconocimientos legales y constitucionales. En Unidad de Estudios INDH (Ed.). Seminario internacional igualdad y no discriminación: Estándares y mecanismos para la igualdad real (pp. 88-134). Santiago: Instituto Nacional de Derechos Humanos.

Chala, J. (2011). La educación cimarrona libre y liberadora: Ruptura epistemológica necesaria (una propuesta en construcción). En L. Mayorga (Ed.): Desde adentro: Etnoeducación e interculturalidad en el Perú y América Latina (pp. 43-55). Lima: CEDET.

Chandola, M. V. (1992). Affirmative Action in India and the United States: The Untouchable and Black Experience. Indiana International \& Comparative Law Review 3, 101-133.

Claro, M. (2005). Acción Afirmativa - Hacia Democracias Inclusivas: Chile. Santiago: EQUITAS.

Claro, M. y Seoane, V. (2005). Acción Afirmativa - Hacia Democracias Inclusivas: Argentina. Santiago: EQUITAS. 
Costa, S. (2007). Vom Nordatlantik zum "Black Atlantic": Postkoloniale Konfigurationen und Paradoxien transnationaler Politik. Bielefeld: transript.

Costa, S. (2012). Freezing Differences: Law, Politics, and the Invention of Cultural Diversity in Latin America. En K. Araujo y A. Mascareño (Ed.). Legitimization in World Society (pp. 139-156). Farnham: Ashgate.

Davis, D., Paschel T. y Morrison, J. (2012). Pan-Afro-Latin African Americanism Revisited: Legacies and Lessons for Transnational Alliances in the New Millennium. En B. Reiter y K. Eison Simmons (Ed.). Afrodescendants, Identity, and the Struggle for Development in the Americas (pp. 19-48). East Lansing (Michigan): Michigan State University Press.

Davis, S. (2003). Racial and Ethnic Inclusion in the Development Agenda. En World Bank. Durban Plus One: Opportunities and Challenges for Racial Ethnic Inclusion in Development (pp. 7-12). Washington: World Bank.

Diaz, M. (2011). Racismo epistémico y monocultura: Notas sobre las diversidades ausentes en América Latina. Revista de Epistemologia y Ciencias Humanas (3), 14-28.

Didou, S. (2008). Pathways en América Latina: Epifanias Locales de un Programa Global. En D. Mato (Coord.). Diversidad cultural e interculturalidad en Educación Superior - Experiencias en América Latina (pp. 459-468). Caracas: IESALC-UNESCO.

Dulitzky, A. (2001). A Region in Denial: Racial Discrimination and Racism in Latin America. Beyond Law, 24, 85-108.

Elkins, Z. y Simmons, B. (2005). On Waves, Clusters, and Diffusion: A Conceptual Framework. The Annals of the American Academy of Political and Social Science 598 (1), 33-51.

Ferranti, D. de (2003). Implications of the Durban Conference for the Bank Group. En World Bank. Durban Plus One: Opportunities and Challenges for Racial and Ethnic Inclusion in Development (pp. 1-6). Washington: World Bank.

Ferranti, D. Perry, G., Ferreira, F. y Walton, M. (2003). Inequality in Latin America and the Caribbean: Breaking with History? Washington: IBRD/World Bank.

Gacitúa, E., Sojo, C. y Davis, S. (Eds.) (2001). Social Exclusion and Poverty Reduction in Latin America and the Caribbean. Washington/San José (Costa Rica): FLACSO/Banco Mundial.

Galanter, M. (1984). Competing Equalities: Law and the Backward Classes in India. Berkeley: University of California Press.

García, J. (2008). La agenda de la afro derecha. América Latina en movimiento. Recuperado el 19 de octubre de 2012, de http://alainet.org/ active/22460\&lang=es

García, J. (2010). Afroepistemología y afroepistemetódica. En S. Walker (Comp.). Conocimiento desde adentro: Los afrosudamericanos hablan de sus pueblos y sus historias, vol. I (pp. 71-87). La Paz: FUNDAFRO. 
Gilroy, P. (1993/2002). The Black Atlantic: Modernity and Double Consciousness. Londres: Verso.

González, N. (2006). Acciones positivas: Orígenes, conceptualización y perspectivas. En: C. de la Torre (Coord.). Derecho a la no discriminación (pp. 307-367). México: UNAM/IIJ.

Guimarães, A. (2005). Racismo e anti-racismo no Brasil, São Paulo: Editora 34.

Hall, Stuart (1996). The West and the Rest: Discourse and Power. En H. Stuart (Ed.). Modernity: Introduction to the Modern Societies (pp. 185-227). Oxford: Blackwell,.

Hall, G. y Patrinos, H. A. (2005). Indigenous Peoples, Poverty and Human Development in Latin America: 1994-2004. Washington: World Bank.

Hanchard, M. (2003). Acts of Misrecognition: Transnational Black Politics, AntiImperialism and the Ethnocentrisms of Pierre Bourdieu and Loïc Wacquant. Theory, Culture \& Society, 20 (4), 5-29.

Hansen, S. (2004). Affirmative Action in Europe: Positive Maßnahmen zur Förderung benachteiligter Personengruppen im Anwendungsbereich der EGRichtlinien 2000/43/EG und 2000/78/EG, Aquisgrán: Shaker.

Harrison, F. V. (2012). Building Black Diaspora Networks and Meshworks for Knowledge, Justice, Peace, and Human Rights. En B. Reiter y K. Simmons (Ed.). Afrodescendants, Identity, and the Struggle for Development in the Americas (pp. 3-18). East Lansing (Michigan): Michigan State University Press.

Hasan, Z. (2009). Politics of Inclusion: Castes, Minorities and Affirmative Action. Oxford: Oxford University Press.

Healey, M. A. (2000).'Disseram que Voltei Americanizada': Bourdieu y Wacquant sobre la Raza en Brasil. Apuntes de Investigación del CECYP, 5, 95-102.

Holst, F. (2012). Ethnicization and Identity Construction in Malaysia. Abingdon/ New York: Routledge.

Inter-American Dialogue (2003, enero). Afro-Descendants in Latin America: How Many? Race Report. Recuperado el 9 de septiembre de 2012 de http:// www.thedialogue.org/page.cfm?pageID $=32 \&$ pubID $=1702 \&$ s $=$

Jackson, D. W. (1999). Affirmative Action in Comparative Perspective: India and the United States. En T. Loenen y P. Rodrigues (Ed.). Non-Discrimination Law: Comparative Perspectives (pp. 249-263). La Haya: Martinus Nijhoff.

Jaramillo, C. (Coord.) (2008). Experiencias de inclusión al medio universitario. Revista ISEES, 3.

Kennedy-Dubourdieu, E. (Ed.) (2006). Race and Inequality: World Perspectives on Affirmative Action. Aldershot (Hampshire): Ashgate.

King, M. L. (1959). My Trip to the Land of Gandhi. En The Martin Luther King, Jr. Papers Project 5 (pp. 231-238). Recuperado el 20 de enero de 2013 
de: http://mlk-kpp01.stanford.edu/primarydocuments/Vol5/July1959_ MyTriptotheLandofGandhi.pdf

Knill, C. (2005). Introduction: Cross-national Policy Convergence: Concepts, Approaches and Explanatory Factors. Journal of European Public Policy 12 (5), 764-774.

Lao-Montes, A. (2009). Cartografias del campo político afrodescendiente en América Latina. Universitas Humanística, (68), 207-245.

Lao-Montes, A. (2011). Reformas de educación superior en busca de la democracia intercultural y la descolonización de la universidad - Debates necesarios, retos claves, propuestas mínimas. En L. Mayorga (Ed.): Desde adentro: Etnoeducación e interculturalidad en el Perú y América Latina (pp. 129-137). Lima: CEDET.

León, M. y Holguín, J. (2005). Acción Afirmativa - Hacia Democracias Inclusivas: Colombia. Santiago: EQUITAS.

León, M. y Hurtado, L. (2005). Acción Afirmativa - Hacia Democracias Inclusivas: Perú. Santiago: EQUITAS.

Lütz, S. (2007). Policy-Transfer und Policy-Diffusion. En A. Benz et al. (Ed.). Handbuch Governance: theoretische Grundlagen und empirische Anwendungsfelde (pp. 132-143). Wiesbaden: VS Verlag für Sozialwissenschaften.

Martin, T. (2001). The Affirmative Action Empire: Nations and Nationalism in the Soviet Union, 1923-1939. Ithaca (Nueva York): Cornell University Press.

Nelken, D. y Feest, J. (Ed.) (2001). Adapting Legal Cultures, Oñati Series, Oxford: Hart Publishing.

Niane, D. T. (Ed.) (1984). General History of Africa IV: Africa from the Twelfth to the Sixteenth Century. Paris/Londres/Berkeley: UNESCO/Heinemann.

Ojeda, D. (2012). Green Pretexts: Ecotourism, Neoliberal Conservation and Land Grabbing in Tayrona National Natural Park, Colombia. Journal of Peasant Studies, 39 (2), 357-375.

Partridge, W., Uquillas, J. y Johns, K. (1996). Including the Excluded: Ethnodevelopment in Latin America. En S. J. Burki (Ed.). Poverty and Inequality Proceedings from the Annual World Bank Conference on Development in Latin America and the Caribbean (pp. 229-252). Washington: Banco Mundial.

Peters, A. y Birkhäuser, N. (2005). Affirmative Action à l`Américaine - Vorbild für Europa? Zeitschrift für ausländisches öffentliches Recht und Völkerrecht 65, 1-34.

Pinho, O. y Figuereido, Â. (2002): Idéias fora do lugar e o lugar do negro nas ciências sociais brasileiras. Estudos afro-asiáticos, 24 (1), 189-210.

Psacharopoulos, G. y Patrinos, H. A. (Ed.) (1994). Indigenous People and Poverty in Latin America: An Empirical Analysis. Washington: Banco Mundial. 
Ribando, C. (2005). Afro-Latinos in Latin America and Considerations for U.S. Policy. CRS Report for Congress RL32713. Washington D.C.: Congressional Research Services.

Rosa Jaimes, V. (2007). El itinerario jurídico de las acciones positivas a la luz del derecho comparado. Derechos Humanos México 5, 43-57.

Said, E. (1978). Orientalism. Nueva York: Pantheon Books.

Sansone, L. (2002). Um campo saturado de tenses: o estudo das relações raciais e das culturas negras no Brasil. Estudos Afro-Asiáticos, 24 (1), 5-14.

Sansone, L. (2003). Blackness Without Ethnicity: Constructing Race in Brazil, Houndmills: Palgrave.

Santos, J. (2002). De armadilhas, convicções e dissensões: as relações raciais como efeito Orloff. Estudos Afro-Asiáticos, 24 (1), 167-187.

Sardar Ali, S. y Rehman, J. (2001). Indigenous Peoples and Ethnic Minorities of Pakistan: Constitutional and Legal Perspectives. Richmond (UK): Curzon.

Schrad, M. L. (2010). The Political Power of Bad Ideas. Oxford/Nueva York: Oxford University Press.

Slate, N. (2012): Colored Cosmopolitanism: The Shared Struggle for Freedom in the United States and India, Cambridge: Harvard University Press.

Sowell, T. (2004). Affirmative Action around the World-An Empirical Study. New Haven/Londres: Yale University Press.

Spedding-Pallet, A. (2011). Descolonización-Crítica y problematización a partir del contexto boliviano. La Paz: ISEAT.

Spiliopoulou Åkermark, A. (1997): Justifications of Minority Protection in International Law. Londres/La Haya/Boston: Kluwer Law International.

Syss, A. (2003). Afro-brasileiros, cotas e ação afirmativa: razões históricas. Rio de Janeiro: Quartet.

Telles, E. (2003). US foundations and racial reasoning in Brazil. Theory, Culture \& Society, 20 (4), 31-47.

Tomuschat, C. (1981). Equality and Non-Discrimination under the International Covenant on Civil and Political Rights. En I. von Münch. Staatsrecht, Völkerrecht, Europarecht: Festschrift für Hans-Jürgen Schlochauer (pp. 691-716). Berlin/ Nueva York: de Gruyter.

Twining, W. (2005). Social Science and Diffusion of Law. Journal of Law and Society, 32 (2), 203-240.

UN Commission on Human Rights (1949). Draft International Covenant on Human Rights - India - Amendment to Article 20, 10 June 1949, E/CN.4/312. Recuperado el 27 de enero de 2011 de: http://daccess-dds-ny.un.org/doc/ UNDOC/GEN/GL9/005/05/PDF/GL900505.pdf?OpenElement. 
U.S. Commission on Civil Rights Briefing Paper on Affirmative Action, Daily Lab. Rep. (BNA) No. 64 at D-33 (abril 4, 1995).

Walker, S. (Comp.) (2010). Conocimiento desde adentro: Los afrosudamericanos hablan de sus pueblos y sus historias, vol. I y II. La Paz: Fundación Pedro Andavérez Peralta.

Walsh, C., Schiwy, F. y Castro-Gómez, S. (Ed.) (2002). Indisciplinar las ciencias sociales: geopoliticas del conocimiento y colonialidad del poder - perspectivas desde lo andino. Quito: Universidad Andina Simón Bolivar/Abya-Yala.

Walsh, C. (2009). Interculturalidad, Estado, Sociedad: Luchas (de) coloniales de nuestra época. Quito: Universidad Andina Simón Bolivar/Abya-Yala.

Walsh, C. (2011a). Acción reparativa en perspectiva afrorreparativa. En Pila Avendaño, V. (Ed.). Pueblos afrodescendientes y derechos humanos: del reconocimiento a las acciones afirmativas (pp. 197-242). Quito: Ministerio de Justicia, Derechos Humanos y Cultos.

Walsh, C. (2011b). Etnoeducación e interculturalidad en perspectiva decolonial. En L. Mayorga (Ed.). Desde adentro: Etnoeducación e interculturalidad en el Perú y América Latina (pp. 93-105). Lima: CEDET.

Wandruszka, A. y Urbanitsch, P. (Ed.) (1980). Die Habsburgermonarchie 1848 - 1918, vol. 3: Die Völker des Reiches. Viena: Verlag der Österreichischen Akademie der Wissenschaften.

Wiesner, L. R. (2005). Un derecho para los débiles: acciones afirmativas y medidas de protección especial en los sistemas norteamericano y colombiano. En C. Sánchez (Ed.). Principios y valores constitucionales (pp. 41-84). Bogotá: Universidad Sergio Arboleda.

Wiesner, L. R. (2007). La acción afirmativa en la Constituyente de 1991. Civilizar 7 (13), 61-80.

Williamson, G. (2007). Acción afirmativa en educación superior: Dilemas y decisiones en tiempos multiculturales de globalización. Ciencias Sociales Online IV (1), 77-101.

World Bank (2005). The Gap Matters: Poverty and Well-Being of Afro-Colombians and Indigenous Peoples. Report No. 33014-CO. Washington: World Bank. 